\author{
ARTIGO \\ CO https://doi.org/10.22481/praxisedu.v15i36.5891
}

\title{
SERIAM OS FUNCIONÁRIOS ACRÍTICOS E DESCONHECEDORES DO QUE FAZ UM ESTUDANTE GOSTAR DE SUA ESCOLA?
}

\author{
WOULD SCHOOL EMPLOYEES BE NON-CRITICAL AND UNAWARE OF WHAT \\ MAKES A STUDENT TO ENJOY SCHOOL?
}

\begin{abstract}
¿SERAN LOS FUNCIONARIOS ACRÍTICOS Y DESCONOCEDORES DE LO QUE HACE QUE UM ESTUDIANTE DISFRUTE DE SU ESCUELA?
\end{abstract}

\author{
Bruno Cajado \\ Universidade Federal da Bahia - Brasil \\ Heitor Lesquives \\ Universidade Federal da Bahia - Brasil \\ Marlécio Maknamara \\ Universidade Federal de Alagoas - Brasil
}

Resumo: Embora tenham conquistado reconhecimento de que também são educadores, os funcionários das escolas ainda são pouco frequentes em pesquisas sobre como sujeitos da educação escolar pensam e atuam. Dito isso, fizemos a indagação aos funcionários de escolas públicas soteropolitanas sobre quais fatores ou aspectos fariam um estudante gostar de sua escola. O material empírico foi constituído por 37 respostas à pergunta "o que faz um aluno gostar de sua escola?" e analisado segundo inspiração da análise de conteúdo. Os resultados foram organizados em oito grupos característicos: múltiplos fatores, assistencialista ou bom tratamento, ensino-aprendizagem, qualidade empresarial-tecnicista, estrutura concomitantemente com ensino-aprendizagem, localidade (segurança), futuro dos discentes, e os próprios alunos. Percebemos também que quase um terço dos funcionários consideram vários fatores agindo concomitantemente pelo bem estar dos estudantes, embora por vezes inspirados de ideias neoliberais. Com tais análises, concluímos que esses funcionários não estão alheios aos problemas (e acertos) das escolas, sendo sujeitos heterogêneos, ativos e críticos.

Palavras chave: Educação escolar. Gosto pela escola. Percepções dos funcionários.

\begin{abstract}
Understand school employees as educators is already a reality, however it is necessary knows more about how these citizens think schools and their work in them. Thereby, we asked employees from Public Schools in Salvador, Bahia, Brazil, about which are the factors or elements that could make students enjoy their school. Hence, this research aimed to analyze and to interpret the 37 answers with the question "what make a student to enjoy your school?". These led to a separation in eight distinct groups, in descending order: multi-factors answers, assistance or good treatment,
\end{abstract}


teaching-learning, business or technical quality, structure concomitantly with teaching-learning, high school location (quality of the locality), students' future, and the students themselves. We noticed that nearly one-third of employees consider several factors acting concurrently for students' well-being, albeit under the influence of business ideas. Thereon, we concluded that these school employees are not out of problems (and hits) in schooling, being heterogeneous individuals, active and critical.

Keywords: Delight about school. Scholar Education. School employees’ opinions.

Resumen: Entender a los funcionarios de las escuelas como educadores ya es una realidad, pero es necesario saber que piensan de la escuela y su trabajo en ella. Para conocer dicha información, hicimos una indagación a los funcionarios de escuelas públicas de Salvador, Bahia, Brasil, para saber cuáles son los factores o aspectos que determinarían que un estudiante tenga interés en la escuela. Esta investigación tuvo por objetivo analizar e interpretar 37 respuestas obtenidas con la siguiente pregunta "¿qué hace que un estudiante disfrute de su escuela?”. Dichas preguntas se dividieron en ocho grupos característicos: múltiples factores; asistencia o buen trato; enseñanza-aprendizaje; calidad empresarial-técnica; infraestructura ligada a la enseñanza-aprendizaje; localidad (seguridad); futuro de los docentes y los propios estudiantes. Se percibió que casi un tercio de los funcionarios consideran que varios de estos factores, actúan al mismo tiempo de manera beneficiosa para los estudiantes, aunque notablemente sobre la influencia de ideas empresariales. De los análisis obtenidos pudimos concluir que los funcionarios no son indiferentes a los problemas (y soluciones) de las escuelas, siendo sujetos heterogéneos, activos y críticos.

Palabras clave: Educación escolar. Disfrutar la escuela. Percepciones de los funcionarios.

\section{Introdução}

A escola, como fabricação histórica, vem apresentando constantes transformações ao decorrer dos tempos. Porém, a necessidade de inovações nos conteúdos didáticos, no ensino, na instrução, na educação como um todo, na sua arquitetura, na formação dos professores, no tempo dos estudantes na escola e em tantos outros fatores pertinentes à vida escolar ainda são requisitados. Para muitos, a escola precisa cativar mais seus alunos, enquanto outros salientam que mesmo com todas suas dificuldades, essa instituição já apresenta meios suficientes para atrair a atenção e desenvolver o interesse dos estudantes para com os assuntos escolares. Mas, afinal, o que faz um aluno ir à escola? Em que sentidos a escola pode ser considerada uma etapa essencial na formação do indivíduo? O que faz o aluno gostar de sua escola?

Como uma escola não só é constituída de docentes e discentes, mas também de um corpo heterogêneo de funcionários, este trabalho teve como objetivo descrever e analisar as diferentes opiniões dos funcionários de escolas públicas de Salvador acerca do que faz um aluno gostar de sua escola. É relevante compreender as concepções desses membros, pois, embora não estejam diretamente envolvidos nos processos didáticos, os mesmos estão 
presentes no cotidiano dos estudantes, tendo importantes participações nos processos de socialização e formação desses indivíduos. Em vista disso, é de suma importância dar voz ativa a esses profissionais, na busca por uma melhor compreensão do ambiente escolar.

Neste artigo objetivamos analisar respostas de funcionários de escolas à pergunta "o que faz um aluno gostar de sua escola". Trazemos inicialmente um referencial teórico abordando a relação de funcionários e a escola brasileira. Em seguida, detalhamos a metodologia usada para a realização da pesquisa e, posteriormente, descrevemos e elencamos detalhadamente os grupos de respostas nos resultados e discussões. Por fim, concluímos este estudo com as considerações finais, trazendo uma síntese do trabalho associada com a nossa crítica sobre o conteúdo abordado e a importância dos funcionários nas escolas brasileiras.

\section{Referencial teórico}

A educação brasileira começou com a catequização dos indígenas pelos Jesuítas, em um ensino idealizado de cunho religioso. Mesmo com as reformas pombalinas (século XVIII), o ensino público continuou restrito a pequenos grupos, com os funcionários sendo da Coroa Portuguesa; as escolas, multisseriadas, permaneceram isoladas até o início do Brasil República (XAVIER, 2013). No século XIX as escolas seriadas surgem, e em 1930 os temas de "educação e democracia" são expostos (XAVIER, 2013). Em 1996 é aprovada a Lei de Diretrizes e Bases da Educação Nacional (LDB, Lei n³94/1996), dispondo sobre a obrigatoriedade e a gratuidade da educação básica, ficando as maiores responsabilidades às esferas públicas (BRASIL, 1996). Todavia, apesar de pública, a escola divulgava a ideologia e os valores da elite dominante no período, procurando construir uma sociedade com mão de obra adestrada para o processo industrial (MOURA et al., 2014a). E esse pensamento, de alienação, perdurou por um longo período, com a função escolar se resumindo a transmitir, de forma teórica, o conteúdo propostos por teóricos à massa (MARTINS, 2005).

Desde 1550, “os primeiros funcionários já se faziam presentes na construção e no funcionamento da primeira escola", no Colégio dos Jesuítas na nossa cidade do Salvador (XAVIER, 2013). No entanto, as suas funções de conservação, alimentação e cuidados gerais eram consideradas "coadjuvantes", devido aos enfoques burocrático e técnico. Essa ideia de atividade secundária perdura até os nossos dias, sendo intensificada com a investida neoliberal de terceirização de suas funções, não ficando mais a cargo direto do Estado. Isso possibilita 
uma maior rotatividade de empregados, o que leva, consequentemente, há uma diminuição do pertencimento dos funcionários às escolas (ALMEIDA, 2009; CNTE, 2009).

Apesar de não trabalharem diretamente em sala de aula com os alunos, os funcionários são responsáveis diretamente pela manutenção e funcionamento do ambiente escolar (LIBÂNEO et al., 2013 apud. MOURA et al., 2014a) desde o início do Brasil na visão ocidental (XAVIER, 2013). Na nossa atual conjuntura educacional voltada à educação integral, há a exigência de "que todos os sujeitos participantes do processo educacional atuem como formadores e educadores" (VIRAGO; COSTA, 2015, p. 1, grifos nossos). Como corroborado em Xavier (2013): “Uma escola não se faz somente de professores e alunos, mas de todo um corpo de profissionais que são necessários e indispensáveis para uma gestão qualificada e democrática".

Em 2009, com a Lei n 12.014 que altera o art. 61 da LDB sancionada, os funcionários devidamente habilitados são reconhecidos como profissionais da educação escolar (CNTE, 2009). Entretanto, há um desafio no que concerne à profissionalização dos faxineiros, cozinheiros, porteiros e seguranças, assim como os são os bibliotecários, diretores, coordenadores e secretários. Como apontado por Almeida (2009), "será que eles conhecem a importância do que fazem para o bom desempenho da escola?”, ou seja, será que os funcionários também sabem que são educadores indispensáveis?

Propostas para colocá-los numa posição de educadores já foram efetuadas, como o curso técnico do programa "Profuncionário" em 2005, promovido pelo Conselho Nacional de Educação/MEC, numa ação conjunta da sociedade (BRASIL, 2005). É preciso, além desses cursos técnicos e do diálogo por eles possibilitados, a "conscientização dos funcionários do seu papel como educadores" (TROJAN; TAVARES, 2007, p. 9), papel esse costumeiramente desvalorizado. Somam-se a necessidade do maior domínio de conteúdos escolares básicos como instrumentos de trabalho e não apenas as suas capacidades braçais.

$\mathrm{Na}$ atualidade, os funcionários administrativos (ou não-docentes) compõem quase que um milhão de funcionários distribuídos em escolas públicas por todos os municípios brasileiros (BRASIL, 2004; XAVIER, 2013). Todavia, preconceitos e barreiras políticas e ideológicas no processo de aprendizagem (CNTE, 2009) como um processo simplista desvinculado da realidade envolvendo apenas a sala de aula e o professor continuam a existir (MALAVASI, 2010). Dito isso, é perceptível que dois grupos são negligenciados: os próprios estudantes, tidos como receptores acríticos do conhecimento vindo dos professores, e os funcionários, vistos como insignificantes no processo de construção do conhecimento 
(XAVIER, 2013); porém, estes pensamentos não podiam estar mais longe da realidade. Desse modo, como possuidores de voz ativa com base na sua vivência na escola e como parte integrante da mesma, os funcionários devem participar do debate sobre "o que faz um aluno gostar de sua escola". Na seção seguinte, descrevemos metodologicamente como se realizou a presente pesquisa.

\section{Metodologia}

O presente trabalho constituiu-se de uma sistematização e análise das respostas obtidas de funcionários não-docentes de colégios públicos de Salvador, Bahia, acerca dos fatores que fazem um estudante gostar de sua escola. Esse artigo faz parte de uma pesquisa maior que envolve, além dos funcionários, docentes, discentes e pais e mães, no sentido de revelar o que pensam tais sujeitos da educação acerca do que faria um aluno gostar de sua escola. A pesquisa figurou como uma das atividades do componente curricular Estágio Supervisionado I do curso de Licenciatura em Ciências Biológicas da Universidade Federal da Bahia (UFBA) durante o semestre letivo de 2017.1. Naquela oportunidade, cada licenciando ficou responsável por coletar respostas dos quatro grupos de sujeitos da educação à pergunta " $O$ que faz um aluno gostar de sua escola?".

A coleta dos depoimentos deu-se a partir de escolha aleatória dos sujeitos, em colégios públicos localizados em diferentes regiões da cidade, que iriam responder a pergunta. As respostas foram escritas pelos próprios entrevistados nas fichas que lhes eram entregues, com exceção de quando eles solicitavam que nós, os entrevistadores, transcrevêssemo-las. De posse das respostas, os licenciandos dividiram-se em quatro equipes (uma para cada grupo de respostas dos sujeitos participantes da pesquisa). Cada equipe ficou responsável por analisar o conteúdo das respostas e, em seguida, apresentar e discutir os resultados de sua análise para toda a turma do componente em questão. Tais retornos trouxeram visões dos diferentes fatores que formam uma escola agradável e prazerosa aos estudantes segundo os sujeitos ligados às escolas públicas. Para elaboração do presente trabalho, alguns licenciandos organizaram-se para uma análise mais aprofundada das respostas obtidas. Esse artigo se debruça sobre as trinta e sete respostas coletadas dos funcionários e analisadas no referido componente curricular. 


\section{Resultados e discussões}

Foi feita uma análise qualitativa das trinta e sete respostas mediante classificação de cada uma delas em grupos de sentido em comum. Desse modo, houve a emersão de oito grupos característicos advindos das concepções dos funcionários acerca da questão "o que faz um aluno gostar de sua escola?". Esses grupos foram intitulados, em ordem decrescente de frequência nas respostas: múltiplos fatores, assistencialista ou bom tratamento, ensinoaprendizagem, qualidade empresarial-tecnicista, estrutura concomitantemente com ensinoaprendizagem, localidade (segurança), futuro dos discentes, e os próprios alunos. A figura 1 mostra o gráfico com a distribuição percentual das 37 respostas nos oito grupos. Para melhor compreensão dos leitores e das leitoras, a análise do grupo múltiplos fatores será a última a ser explanada.

Figura 1: Gráfico quantitativo das frequências de respostas nos diferentes grupos acerca do que faz um aluno gostar de sua escola, segundo os funcionários de escolas públicas de Salvador.

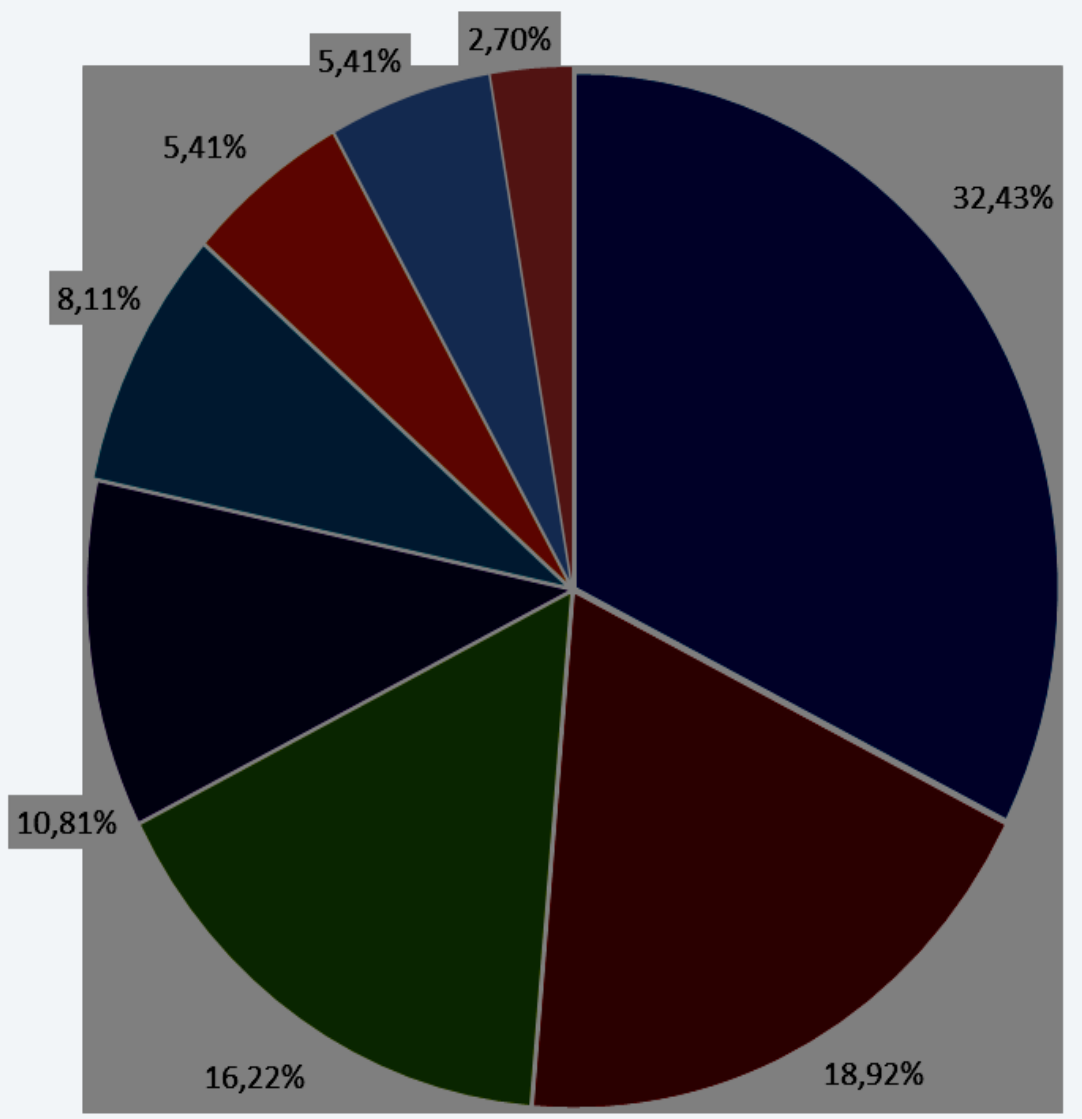

- Múltiplos Fatores

- Assistencialista/Tratamento

- Ensino Aprendizagem

- Empresarial-Tecnicista

- Estrutura + Ensino Aprendizagem

- Localidade (Segurança)

- Futuro dos discentes

- Aluno

Fonte: os autores.

Grupo 1: Assistencialista ou Bom tratamento 
Para este grupo, foram alocadas as respostas que evidenciavam um cuidado para com os estudantes como elemento de possível gosto deles pela escola, segundo os funcionários. Esse cuidado apareceu expresso em elementos como a orientação, o zelo, alimentação, estadia e o oferecimento de lazer por parte da escola. A proximidade da instituição com a população foi bem abordada nesse grupo, como exemplificado pelo F1:

F1: Uma boa alimentação, os amigos, o carinho dos funcionários e professores tem [sic] por eles. O desempenho dos professores em relação ao ensino deles, ou seja, a forma como os professores se empenham para fornecer ensino de qualidade, além do carinho que todos tem [sic] por eles.

Segundo Beltrão (2014), no Capítulo III da Constituição Federal (CF), seção I, artigo 206, que trata da educação, está escrito que o ensino será ministrado com base em alguns princípios. Dentre eles, se destacam a igualdade de condições para o acesso e permanência na escola, garantia de padrão de qualidade, valorização dos profissionais da educação escolar e liberdade de aprender e ensinar, pesquisar e divulgar o pensamento da arte e do saber. Logo, esses parâmetros demonstram a preocupação da sociedade brasileira, refletida tanto na $\mathrm{CF}$ como na LDB, de que haja no país uma educação pública, gratuita, universalizada, com valorização dos trabalhadores e de qualidade. As palavras de F2 remeteram a essa expectativa social sobre a escola:

F2: Uma escola dinâmica, com boas ações, que tenha diálogo entre direção, professores e até mesmo funcionários. Professores coerentes que estejam abertos ao diálogo. Enfim, uma escola amiga dos pais e de todos.

O UNICEF (Fundo das Nações Unidas para a Infância) publicou em 2004 um documento, cujo título é "Indicadores da Qualidade na Educação", no qual apresenta alguns tópicos que a escola precisa enfatizar para ser considerada uma instituição de qualidade. Um deles afirma que a escola é um espaço de ensino-aprendizagem e de vivência de valores, onde os indivíduos convivem com os demais jovens, além dos professores e funcionários, estabelecendo assim o diálogo proposto na resposta elencada anteriormente. Em contestação a esta ideia, Beltrão (2014) alega que não existe um padrão ou uma receita para uma escola de qualidade e que este conceito é dinâmico, ou seja, cada escola precisa ter autonomia para 
refletir, propor e tomar ações em busca dessa qualidade. Sendo assim, não podemos especifisicar sem riscos de arbitrariedades e homogeneização tais qualidades, pois elas podem ser um tanto quanto subjetivas. Porém, temos noções de conhecimentos atitudinais que a escola pode oferecer para seus alunos para tornar esse ambiente escolar mais aprazível, além de dispor de parâmetros que emergem da própria fala dos sujeitos envolvidos com a educação escolar, tal como visto aqui.

\section{Grupo 2: Ensino-Aprendizagem (resposta focada no Professor)}

Nessa categoria, para $16 \%$ dos funcionários, o professor e sua didática é que instigariam o aluno a gostar de sua escola. Segundo alguns funcionários, para que esse gosto aconteça, seria relevante que o professor associasse os assuntos dados em aula com o cotidiano de seus alunos como relatado a seguir:

F3: Propostas interessantes que estimulem o aprendizado, contextualizando o conteúdo à rotina.

Segundo Fazenda (1998), muitos alunos têm vivenciado a "aprendizagem como se os elementos culturais que dão conteúdo a seu saber fossem estanques e oriundos de fontes isoladas entre si". Ainda para esta autora, existe também o problema da falta de interdisciplinaridade entre conteúdos e até com a vida dos alunos, causando, de certa forma, o desinteresse dos jovens. Esta abordagem didática é importante para a compreensão, por parte dos alunos, de que a escola não está isolada dos problemas de seu cotidiano, podendo a mesma apresentar maneiras de solucionar ou enfrentar esses impasses.

O fato de alguns docentes costumarem desconsiderar a individualidade de cada estudante é um erro cometido por muitos profissionais que acabam transformando suas aulas em um protocolo a ser seguido em todas suas turmas. Com isso, Dayrell (2001) em seu estudo declara que cada um dos jovens, ao chegar à escola, é fruto de um conjunto de experiências sociais vivenciadas nos mais diferentes espaços sociais. Para existir uma boa convivência em sala de aula é preciso compreender os jovens e apreendê-los como sujeitos socioculturais: "trata-se de compreendê-lo [o sujeito] na sua diferença, enquanto indivíduo que possui lógicas de comportamentos e hábitos que lhe são próprios” (DAYRELL, 2001, p. 140).

Alguns autores (CARVALHO, 1989; BENETTI, 2002) salientam que alunos e até professores acham a sala de aula um ambiente entediante, sem atração. Por consequência, 
muitos funcionários citaram que as aulas dinâmicas (incluindo as saídas de campo) proporcionadas pelos professores cativam seus alunos, estimulando-os a gostarem da escola:

F4: $O$ que faz o aluno gostar da escola é a participação deles nas atividades dinâmicas, nos projetos itinerantes, aulas de campo, dentre outros.

F5: Projetos. Aulas de campo. Gincana. Professores dedicados e compreensivos. Aula [sic] atrativas / expositiva.

Assim, percebe-se que a didática dos professores é um quesito influenciador no envolvimento do aluno com sua vida escolar, segundo os funcionários. Para isso, esses profissionais deveriam usar diversas estratégias (de método e de recurso didático) para tornarem suas aulas mais prazerosas e eficientes. Aulas essas que não se restringem ao espaço da sala de aula e tampouco ao ambiente escolar (aulas de campo), além de abarcar atividades em grupos (e não individuais), como os projetos e gincanas.

\section{Grupo 3: Regido pelo pensamento de qualidade empresarial-tecnicista}

Esse grupo, como Moura e colaboradores (2014a) dizem, utiliza-se bastante do modelo fabril, valorizando ideias de bons professores e de bom chefe (o diretor) como requisitos ao gosto de alunos por sua escola. A escola precisa estar em dia, para conquistar novos cidadãos clientes, clientes esses que geram um gasto, segundo os indicadores de investimentos (OLIVEIRA; ARAUJO, 2005). É o grupo de respostas em que as estratégias organizacionais e institucionais deveriam ser utilizadas para conquistar os chamados clientes, segundo os funcionários que participaram desta pesquisa.

F6: $O$ tratamento dos funcionários, dos professores, da direção da escola. [...] Uma boa direção! Sem uma boa direção, o aluno fica solto, não há controle e bom desempenho. Aulas de música, tempo integral.

Numa análise superficial, parte das respostas deste grupo poderiam se encaixar como múltiplos fatores. Todavia, diferentemente dos múltiplos fatores, as respostas presentes nessa categoria de qualidade empresarial têm um eixo norteador, voltado sempre à qualidade do que é oferecido (OLIVEIRA; ARAUJO, 2005). O tratamento, a direção, as aulas integrais e a 
disciplina são percepções comuns entre os entrevistados, todas focadas entre bom/ruim, adequado/inadequado, disciplina/indisciplina etc. Podemos extrapolar essas ideias baseadas no pensamento comercial de oferecimento de um serviço, sendo todos os funcionários em prol dos clientes (os alunos):

F7: A aprendizagem com qualidade, professores que ensinam com amor, paciencia [sic], chama o aluno p/ escola pública. A disciplina da coordenação pedagogica [sic], vice-direção, secretaria.

Esse pensamento, atribuído unicamente como o fator responsável pelos alunos gostarem de sua escola por mais de $10 \%$ dos funcionários, está arraigado na ideia de qualidade do ensino cuja lógica é sinônimo de eficiência e produtividade. Essa matriz, empresarial, enfatiza a maior produtividade, com controle sobre o produto e menor custo. Esses princípios preteridos são opostos aos democráticos (MALAVASI, 2010), sendo esse o almejado para um projeto efetivo de emancipação e inserção social de todos.

\section{Grupo 4: Estrutura concomitante com ensino-aprendizagem}

Apesar de termos um grupo de ênfase ao ensino-aprendizagem (o grupo 2), em 8,11\% das respostas houve uma singularidade. Para esses funcionários o processo de ensinoaprendizagem figura sempre vinculado à qualidade da estrutura do colégio quando se trata de falar do que faria um aluno gostar de sua escola. Como explanado por Zan e Possato (2014), a arquitetura escolar tem uma função muito importante na composição do ambiente escolar; esses funcionários parecem reconhecer esse aspecto e ele sempre aparece concomitantemente ao que se passa em sala de aula, em "atividades que estimulem o conhecimento", mediado pelos professores:

F8: Bom ensino, boa estrutura, bons recursos didáticos.

F9: Um ensino de qualidade, estrutura adequada, salas bem organizadas.

Esse pensamento é coerente quando se soma o aporte estrutural com a necessidade do ensino aprendizagem, numa ênfase empresarial, do bom e do adequado. Isso pode estar associado à relação direta da sala de aula (espaço físico) à própria aula (ensino- 
aprendizagem), na construção de instalações gerais adequadas às atividades escolares (DOURADO; OLIVEIRA, 2009). É perceptível também o caráter genérico das respostas, em um panorama generalista.

\section{Grupo 5: Localidade (segurança do bairro)}

Talvez por uma das escolas situar-se em um bairro nobre de Salvador, obtivemos duas respostas de funcionários que opinaram que o motivo dos estudantes gostar da sua escola é a localidade da mesma.

F10: Lugar central. Onde moram em outros bairros violentos não querem ficar no bairro, dessa forma vão para essa escola.

F11: Localidade não muito perigosa durante o dia. Centro da cidade.

Segundo Njaine e Minayo (2003), algumas escolas públicas convivem mais seriamente com o problema da violência entre alunos. Essa violência local ocorre especialmente naquelas que se encontram próximas aos locais de tráfico de drogas e que experimentam diariamente o medo e a ameaça de forças externas na comunidade. Logo, com isso, dá-se a interpretar que muitos responsáveis optam por matricular seus filhos em escolas em bairros mais seguros - os nobres -, com policiamento contínuo, como relatado pelos funcionários supracitados. Respostas desse tipo não figuraram nos funcionários de escolas de bairros periféricos.

Em oposição a essa ideia, Sposito (1998) afirma que a violência nas escolas não se dá somente em bairros periféricos e que registros de violência escolar também são feitos em locais considerados mais nobres. De acordo com a mesma autora, a violência ocorre devido à exacerbação da desigualdade social encontrada nessa situação, onde excluídos e incluídos convivem no mesmo lugar. Porém, não podemos afirmar se nas escolas do nosso universo amostral há muitos registros de violência, pois, apesar de ser uma questão válida, não foi o foco de nossa pesquisa.

\section{Grupo 6: Preparação para o Futuro dos discentes (Cidadania / Profissionalizante)}

Para um grupo pequeno de funcionários $(5,41 \%)$, a razão para os alunos gostarem de sua escola é pelo fato dos mesmos acreditarem que a Instituição irá prepará-los para o futuro. 
Porém, há divergência entre o foco dessa preparação. Alguns afirmam que os jovens devem ser educados para exercer seu papel de cidadão, enquanto outros acreditam que deveriam ser treinados para o mercado de trabalho (visão tecnicista da escola).

Para Beltrão (2014), a educação deve ser entendida como uma efetivação da cidadania, ou seja, os gestores, o corpo docente, os demais funcionários e a comunidade devem promover o desenvolvimento de socialização dos jovens, para que os mesmos, futuramente, possam participar da construção de uma sociedade mais justa e igualitária. Como Ribeiro (2002) também afirma, a educação escolar é via principal de conquista da igualdade de direitos, portanto, da cidadania. Desse modo, a escola é o lugar onde os jovens aprendem a respeitar o próximo e com isso abre-se o espaço para a igualdade de direito e oportunidade de fazer novas amizades, como afirma um funcionário:

F12: A necessidade de um futuro melhor. É o lugar onde eles se sentem na $2^{a}$ casa e tem mais facilidade de fazer amizade.

Arroyo (2007) declara que muitos possuem a ideologia de que a escola (ou a escolarização) é a chave que abrirá as portas para um bom emprego e melhores condições de vida, como observado na fala do sujeito entrevistado:

F13: As aulas, um ensino da melhor qualidade proporcionando eles pro mercado de trabalho, para eles poder [sic] participar de uma seleção e não tem [sic] nenhum medo se vai dar certo, e conhecimentos que ele vai ter pra vida toda que é um bem que ninguém pode tomar.

Ainda segundo Arroyo (2007) os pais que tiveram menor tempo de escolarização ainda defendem esse argumento, entretanto, essa visão está sendo desconstruída. Segundo ele, a mídia, as políticas públicas e as políticas educativas ainda continuam insistindo na crença de que a escola é a fonte de mudanças e melhoria de vida. Por esse conceito ainda ser incitado em ampla esfera, muitos jovens acabam direcionando seu foco apenas pra ingressar em um curso de nível superior ou técnico, mesmo sendo contra sua vontade. Isto é, os mesmos acabam construindo um contestável conceito de que só quem possui maior escolaridade se tornará bem sucedido, o que pode ser desestimulador a esses jovens estudantes. 


\section{Grupo 7: Aluno}

Nesse grupo, representado por apenas uma resposta, a responsabilidade e as características que fazem um aluno gostar da sua escola estão no próprio aluno, ficando indiferente às condições e aos fatores socioculturais em que os alunos e a escola estão inseridos:

F14: É o aluno que gosta de estudar. O aluno que estuda não tem escola ruim pra ele.

Silva e colaboradores (2014, p. 1880) trazem a necessidades de ações que "considerem o cotidiano dos alunos e seus sistemas de pensamento sobre fenômenos, conteúdos e procedimentos da educação escolar, incluindo seu próprio gosto pela escola”. Porém, como evidenciado na resposta de F14, o gosto do aluno não está ligado à necessidade de ver inserido o seu gosto na escola, mas nele próprio, como algo intrínseco e independente do restante, numa clara ideia individualista e romantizada. Esse pensamento pode se reverberar, a nosso ver, em atitudes estereotipadas ao se ignorar o caráter social em que estamos inseridos e os múltiplos fatores que compõem uma escola.

\section{Grupo 8: Múltiplos Fatores}

Diante de todos os fatores supracitados, quase $1 / 3$ dos funcionários $(32,43 \%)$, classificaram como vários os fatores que fazem um aluno gostar de sua escola. Esses sujeitos confirmam em suas respostas que têm conhecimentos dos inúmeros fatores que interferem igual e concomitantemente na qualidade dessas instituições (MOURA et al., 2014b). Essa pluralidade se vincula ao entendimento de sujeitos como espaços múltiplos, "que compreende diferentes atores, espaços e dinâmicas formativas [...]" (DOURADO; OLIVEIRA, 2009, p. 203).

Dentre as características mencionadas, estão segurança, localização, gincana, merenda, tratamento, material didático, espaço físico e relação professor-aluno. Segundo esses sujeitos, a qualidade da educação é um fenômeno complexo, multifatorial que envolve múltiplas dimensões (MOURA et al., 2014a). Esses fenômenos múltiplos podem ser evidenciados, em frases curtas, de sentido amplo e genérico:

F15: Uma boa gestão. Uma boa localidade (fácil acesso). Professores capacitados. *Merenda de qualidade. Segurança. 
A questão da merenda, enfatizada na resposta original do F15 por um asterisco, foi citada em quatro das doze respostas desse grupo. A questão da segurança, apesar de nunca ter aparecido isoladamente, também foi citada quatro vezes, que, juntamente com a lembrança de que os alunos são de bairros periféricos, enfatiza a ideia de diferença entre o ambiente que o aluno vive e o ambiente em que ele estuda (no centro da cidade). F16 exemplifica uma ideia mais específica, com ideas plurais de genéricas à minimamente detalhadas:

F16: Cursos diversificados. Projetos. Estruturas. Jogos. Infraestrutura. Bons professores responsáveis $\rightarrow$ boa relação prof-aluno por interesse. Incentivo de matérias diversificadas $\rightarrow$ interesselestimula prender [sic] à escola.

A relação professor-aluno, juntamente com a capacitação dos professores e a oferta de cursos técnicos foram citadas repetidas vezes. Algumas respostas estavam em forma de textos discursivos ([...] Boas práticas de ensino que vão permitir a esses alunos um futuro melhor, pois eles estarão aptos [...]), mas outras eram curtas ou até em tópicos com uma única palavra. Com isso, compreendemos que essas respostas de linguagem simples e fragmentada expõe a dificuldade que eles apresentam de expor o seu ponto de vista nas questões cotidianas, na qual eles presenciam todos os dias, como o F17:

F17: Alguns de estudar. Gincana. Conversar com os amigos. Bagunça. Merenda.

A escola é construída por um conjunto de variáveis, que fazem sentido quando juntas, e não isoladas do meio, para que haja resultados. Em muitas das respostas, atividades extracurriculares foram citadas, como as gincanas e as bagunças feitas pelos próprios alunos em sua ocupação do espaço escolar. Como afirmado por Dayrell (2001), nenhum espaço além da sala de aula é costumeiramente pensado como dotado de funções pedagógicas. Porém, é sabido que os estudantes ressignificam esses ambientes, com uma pluralidade de funções e usos, que ressoam nos atos por eles praticados, o que é passível de percepção na relação funcionário-aluno (além de toda a vivência anterior do funcionário como aluno). 


\section{Considerações finais}

Este trabalhou teve o propósito de ouvir os funcionários de escolas públicas a respeito do que eles pensam a respeito do que $f a z$ um aluno gostar de sua escola. Foi surpreendente e gratificante perceber que quase um terço desses sujeitos credita a "múltiplos fatores" a possibilidade de um aluno vir a gostar de sua escola. Isso é bastante interessante, pois, ao mesmo tempo em que demonstra a atenção dos funcionários às diferentes atividades e anseios dos alunos, mostra a dificuldade de restringir a multidimensionalidade da questão a apenas uma ação.

Muitas dessas respostas estavam ligadas ao ideal da qualidade escolar, sobre diversas funções, tanto físicas (estrutura, material didático) quanto das interações com as pessoas e das suas sensações (como a relação professor-aluno, tratamento, atividades extracurriculares). É evidente que buscamos a qualidade escolar, qualidade esta onde todos "possam em um mesmo espaço público ter seus direitos assegurados e a educação, direito inalienável do ser humano, garantidos, independentemente do nível sócio econômico ao qual pertençam" (MALAVASI, 2010, p. 85). Para se almejar esse objetivo coletivo - e não a mesquinhez da "aprendizagem mínima para a sobrevivência”, como exigida pelo Banco Mundial (MOURA et al., 2014c, p. 773) - os funcionários precisam se fazer presentes e sugerem estar atentos a essa necessidade de, como indivíduos ativos e críticos, passarem a ter uma ação formativa dentro da escola (MOURA et al., 2014a; VIRAGO; COSTA, 2015).

Com o presente trabalho, é perceptível que os funcionários, por vezes ignorados no desenvolver das atividades escolares, são sujeitos ativos e críticos, precisando apenas ser ouvidos pelos administradores escolares, para que a discussão da nossa escola contemporânea não caia em discussões que não alcancem a diversidade de vozes e de percepções acerca dos diferentes elementos que compõem os cotidianos escolares. Tivemos a oportunidade de perceber e refletir sobre a diversidade de respostas; todavia, como se é esperado em qualquer pesquisa, há várias indagações ainda a responder, tais quais: em que podemos contribuir para efetivamente aproximar e melhorar a escola aos anseios dos alunos? Quais as mudanças no pensamento dos funcionários com o passar dos anos no serviço público? Considerando que reconhecer o ambiente escolar como um campo de debates e discussões políticas é uma das premissas para uma escola de qualidade, esperamos ter contribuído para alimentar o debate acerca da polifonia que atravessa o que se pensa e o que se faz em nossas escolas. 


\section{REFERÊNCIAS}

ALMEIDA, Daniela. Funcionários dos serviços de apoio. Nova Escola, v.3, 2009. Disponível em: < http://gestaoescolar.org.br/conteudo/750/funcionarios-dos-servicos-de-apoio> Acesso em: 12 jan. 2018.

ARROYO, Miguel. A escola é importantíssima na lógica do direito à educação básica. In: COSTA, M. V. (Org.). A escola tem futuro? 2. ed. Rio de Janeiro: Lamparina, 2007. p. 119149.

BELTRÃO, Rinaldo. Técnico em Multimeios Didáticos e Secretaria Escolar: Funcionários de Escolas: Cidadãos, Educadores, Profissionais e Gestores. Secretaria de Educação, Pernambuco, 2014.

BENETTI, Bernadete. A temática ambiental e os procedimentos didáticos: perspectivas de professores de Ciências. In: VIII Encontro perspectivas do Ensino de Biologia, São Paulo. Anais. São Paulo: FEUSP, 2002.

BRASIL. Congresso Nacional. Lei no 9.394 de 20 de dezembro de 1996. Lei de Diretrizes e Bases da Educação Nacional. Ministério da Educação e do Desporto. Brasília, 1996.

BRASIL. Ministério da Educação e Cultura. Por uma política de valorização dos trabalhadores em educação: em cena, os funcionários de escola. MEC/SEB. Brasília, 2004.

BRASIL. Ministério da Educação. Funcionários de escolas: cidadãos, educadores, profissionais e gestores/elaboração. Universidade de Brasília, Brasília, 2005.

CARVALHO, Luiz Marcelo. A temática ambiental e a escola do $1^{\circ}$ grau. 286f. Tese (Doutorado em Educação). Faculdade de Educação, Universidade de São Paulo, 1989. Orientadora: Prof ${ }^{a}$. Dra ${ }^{a}$. Myriam Krasilchik.

CNTE - Confederação Nacional dos Trabalhadores em Educação. Funcionários de escola: trajetória e desafios da profissionalização. Revista Retratos da Escola, v. 3, n. 5, p. 493-500, Brasília, 2009.

DAYRELL, Juarez. A escola como espaço sócio-cultural. In: DAYRELL, Juarez (Org.). Múltiplos olhares sobre educação e cultura. Belo Horizonte: Editora UFMG, 2001, p. 136161.

DOURADO, Luiz; OLIVEIRA, João. A qualidade da educação: perspectivas e desafios. Cad. Cedes, v.29, n.78, p. 201-215, 2009.

FAZENDA, Ivani Catarina Arantes. O conhecimento pedagógico e a interdisciplinaridade: o saber como intencionalização da prática. In: FAZENDA, Ivani Catarina Arantes (Org.) Didática e Interdisciplinaridade. Campinas: Papirus, 1998, p. 31-44.

MALAVASI, Maria. Avaliação institucional de qualidade potencializada pela participação dos vários segmentos da escola. In: DALBEN, Ângela et al. (Orgs.). Convergências e 
tensões no campo da formação e do trabalho docente. Belo Horizonte: Autêntica, 2010, p. 85-103.

MARTINS, Pura Lúcia. Conteúdos Escolares: a quem compete a seleção e a organização? In: VEIGA, Ilma (Org.). Repensando a Didática. 22ª ed. Campinas, SP: Papirus. 2005, p. 75-91.

MOURA, Angelica; PEREIRA, Josélia; BEZERRA NETO, Miguel; MAKNAMARA, Marlécio. "O que é uma escola de qualidade?": com a palavra, funcionários de escolas públicas do RN. Revista da SBEnBio, n.7, p.758-768, 2014a.

MOURA, Angelica; SOUZA, Cassiana; PEREIRA, Josélia; MAKNAMARA, Marlécio. Pais e mães, a vez e a voz: como eles qualificam uma escola. Revista da SBEnBio, n.7, p. 42574266, 2014b.

MOURA, Angelica; PEREIRA, Josélia; MAKNAMARA, Marlécio. Escola de Qualidade: o que docentes têm a dizer sobre ela?. Revista da SBEnBio, n.7, p. 769-778, 2014c.

NJAINE, Kathie; MINAYO, Maria. Violência na escola: identificando pistas para prevenção. Interface - Comunic, Saúde, Educ, v.7, n.13, p.119-34, 2003.

OLIVEIRA, Romualdo; ARAUJO, Gilda. Qualidade de ensino, uma nova dimensão na luta pelo direito à educação. Revista Brasileira de Educação, n. 28, 2005.

RIBEIRO, Marlene. Educação para a cidadania: questão colocada pelos movimentos sociais. Educação e Pesquisa, São Paulo, n.2, p. 113-128, 2002.

SILVA, Anaily; SOUZA, André; DANTAS, Andrielly; SOUZA, Cassiana; OLIVEIRA, Hugo; MACÊDO, Ewerton; MAKNAMARA, Marlécio. Motivos para um aluno ir à escola: o que dizem docentes e funcionários. Revista da SBEnBio, n.7, p. 1878-1889, 2014.

SPOSITO, Marília. A instituição escolar e a violência. Cadernos de Pesquisa, São Paulo, n. 104, p. 58-75, 1998.

TROJAN, Rose Meri; TAVARES, Tais Moura. O funcionário escolar como educador: formação dos trabalhadores em educação da rede estadual de ensino. Revista Eletrônica de Extensão, Florianópolis, v. 4, n. 5, 2007.

UNICEF. Indicadores da qualidade na educação. Ação Educativa, UNICEF, PNUD, INEPMEC (coordenadores), São Paulo, 2004.

VIRAGO, Carine; COSTA, Carla. A importância dos funcionários no processo educativo nas escolas. Congresso Internacional de Educação Popular do MOBREC/SM, Santa Maria, 2015, p. 1-5.

XAVIER, Nubia. Funcionário docente e não-docente: uma relação de poder. Portal Educação, São Paulo, 2013. Disponível em: < https://www.portaleducacao.com.br/conteudo/artigos/direito/funcionario-docente-e-naodocente-uma-relacao-de-poder/52716>. Acesso em: 28 ago. 2017.

ZAN, Dirce; POSSATO, Beatris. Espaços cerrados: as marcas da violência e do controle na arquitetura das escolas. E-curriculum, São Paulo, v. 12, n. 03, p. 2176-2191, 2014. 


\section{Agradecimentos}

Os autores são gratos aos demais estudantes do componente curricular Estágio Supervisionado I para Ciências Biológicas, que tornaram possível essa coleta de dados em variados colégios de Salvador. BC é grato a Letícia Costa, Fiorella Collas, Estácio Gouveia e Letícia e Clemilda Cajado, e HL agradece a Carmen Toledo, Márcio Lesquives e Emanuele Araújo por todo o apoio.

\section{SOBRE OS AUTORES}

\section{Bruno Cajado}

Mestrando em Biodiversidade e Evolução, Instituto de Biologia, Universidade Federal da Bahia (UFBA), Salvador, Bahia, Brasil; Programa de Pós Graduação em Biodiversidade e Evolução (PPGBioEvo); Grupo de Pesquisa ESCRE(VI)VER: Grupo de Estudos e Pesquisas com Narrativas em Educação/CNPq; cajadobruno96@gmail.com

(iD) http://orcid.org/0000-0001-5767-0791

\section{Heitor Lesquives}

Mestrando em Ecologia aplicada à Gestão Ambiental, Instituto de Biologia, Universidade Federal da Bahia (UFBA), Salvador, Bahia, Brasil; Programa de Pós-graduação em Ecologia e Biomonitoramento; Grupo de Pesquisa ESCRE(VI)VER: Grupo de Estudos e Pesquisas com Narrativas em Educação/CNPq; heitorlesquives@ hotmail.com

iD http://orcid.org/0000-0002-7368-2888

\section{Marlécio Maknamara}

Pós-doutorado na School of Education da La Trobe University com Bolsa Estágio de Professor Visitante no Exterior (CAPES/PVEx); Universidade Federal de Alagoas, Maceió, Alagoas, Brasil; Programa de Pós-Graduação em Educação/UFBA e Programa de PósGraduação em Educação/UFRN; Líder do ESCRE(VI)VER: Grupo de Estudos e Pesquisas com Narrativas em Educação/CNPq. Correio eletrônico: maknamaravilhas@gmail.com

iD http://orcid.org/0000-0003-0424-5657

Recebido em: 19 de abril de 2018 Aprovado em: 21 de setembro de 2019 Publicado em: 03 de dezembro de 2019 